\title{
TEKNOLOGI PENANGKAPAN BARONANG RAMAH LINGKUNGAN DI KEPULAUAN SERIBU
}

\section{THE SUISTAINABLE TECHNOLOGY FISHERIES OF RABBITFISH IN SERIBU ISLANDS}

\author{
Oktavianto P. Darmono ${ }^{1}$, M. Fedi A. Sondita ${ }^{2}$, Sulaeman Martasuganda ${ }^{2}$ \\ ${ }^{1}$ Program Studi Teknologi Perikanan Laut, Sekolah Pascasarjana \\ ${ }^{2}$ Departemen Pemanfaatan Sumberdaya Perikanan, \\ Fakultas Perikanan dan Ilmu Kelautan, Institut Pertanian Bogor \\ Korespondensi: prastejo@gmail.com
}

\begin{abstract}
Fisheries utilization of rabbitfish is one of the big potential resource in Seribu Island. Catch production of rabbitfish in the Thousand Islands has increased, it was influenced by market demand. The impact of continuously rabbitfish exploration is habitat destruction. The aim of research were an inventory fishing gear types for rabbitfish and determine sustainable level of rabbitfish fishing unit. The research method was survey. It was conducted in February-March 2015 and November-December, 2015. Analysis data which used to inventory fishing gear types of rabbitfish in Seribu Islands was descriptive analysis; Sustainable level was analyzed by nine criteria of FAO. The results showed that fishing gear which caught rabbitfish in Seribu Islands were muroami, bamboo traps, wire traps, net traps, surrounding nets, and speargun. Bamboo traps was the most sustainable fishing gear with a score 25.75 , based on sustainability levels.
\end{abstract}

Keyword: fishing gear, rabbitfish, seribu island, sustainable fishing technology,

\begin{abstract}
ABSTRAK
Pemanfaatan sumber daya perikanan baronang di Kepulauan Seribu menjadi salah satu potensi perikanan tangkap yang cukup besar. Penangkapan baronang di Kepulauan Seribu mengalami peningkatan, hal ini dipengaruhi harga baronang yang meningkat akibat dari permintaan pasar akan baronang meningkat. Kegiatan eksplorasi penangkapan baronang secara terus-menerus mengakibatkan kerusakan habitat penangkapan. Tujuan penelitian inventarisasi jenis alat tangkap baronang serta menentukan tingkat keramahan lingkungan unit penangkapan ikan baronang. Metode penelitian yaitu survey. Penelitian dilaksanakan pada bulan Februari-Maret 2015 dan November-Desember 2015. Analisis data yang digunakan yaitu deskriptif untuk menginventarisasi jenis alat tangkap ikan baronang di Kepulauan Seribu; Analisis tingkat keramahan lingkungan berdasarkan sembilan kriteria FAO. Hasil penelitian menunjukkan jenis alat tangkap ikan yang menangkap baronang di Kepulauan Seribu adalah alat tangkap muroami, bubu tambun, bubu kawat, bubu jaring, jaring lingkar, dan speargun. Tingkat keramah lingkungan jenis alat tangkap bubu tambun merupakan alat tangkap yang paling ramah lingkungan dengan nilai skor 25.75.
\end{abstract}

Kata kunci: alat tangkap, baronang, Kepulauan seribu, teknologi penangkapan ramah lingkungan, 


\section{PENDAHULUAN}

\section{Latar belakang}

Pemanfaatan sumber daya perikanan baronang di Kepulauan Seribu menjadi salah satu potensi perikanan tangkap yang cukup besar. Ikan baronang banyak ditemukan di perairan dangkal, pesisir hingga tubir pantai (Arthana 2009). Mayunar (1992) menyatakan bahwa ikan baronang di Indonesia baru ditemukan 12 jenis yang dikumpulkan dari Teluk Banten, Tanjung Pinang, Ujung Pandang dan Kepulauan Seribu. Jenis ikan baronang yang banyak ditemukan di Kepulauan Seribu adalah $S$. guttatus, $S$. canaliculatus, $S$. javus, $S$. virgatus, $S$. fuscescens, dan $S$. vermiculatus.

Lokasi utama tangkapan nelayan adalah sekitar Pulau Pramuka, Semak Daun, Karang Congkak, Karang Bongkok, dan Karang Beras. Kawasan ini merupakan daerah yang masih memiliki ekosistem lamun dan karang dengan kondisi habitat yang cukup baik untuk kehidupan baronang. Beberapa gugusan pulau tersebut sering dijadikan tempat wisata snorkling dan diving, sehingga kondisi karang masih sangat baik untuk habitat ikan baronang (Purnomo et al. 2013). Jenis alat tangkap ikan karang yang ada di Kepulauan Seribu adalah muroami (Iskandar dan Puspita 2009), bubu (Riyanto 2009), speargun, jaring lingkar (tegur). Penangkapan baronang di Kepulauan Seribu mengalami peningkatan, hal ini dipengaruhi harga baronang yang meningkat akibat dari permintaan pasar akan baronang meningkat. Kegiatan eksplorasi penangkapan baronang secara terus-menerus mengakibatkan kerusakan habitat penangkapan.

Aktivitas penangkapan terhadap ikan baronang dapat mempengaruhi perubahan struktur populasi dari sumberdaya ikan baronang, antara lain dapat dilihat dari ukuran ikan, jumlah hasil tangkapan nelayan dan umur ikan yang tertangkap. Hal ini yang mengakibatkan sebagian besar ikan-ikan yang ada di perairan menjadi berkurang jumlahnya, sehingga diperlukan pengelolaan yang didasarkan informasi biologis untuk mempertahankan kelestarian populasi ikan baronang, khususnya di ekosistem terumbu karang dan padang lamun. Teknologi penangkapan ikan yang ramah lingkuangan merupakan salah satu langkah dalam keberlanjutan penangkapan ikan, sehingga tetap menjaga keseimbangan sumber daya ikan tanpa mempengaruhi kualitas lingkungan hidup.

Agar pemanfaatan sumberdaya ikan baronang di perairan Kepulauan Seribu tetap lestari maka penggunaan alat tangkap ikan baronang perlu dilakukan analisis keramah lingkungan. Berdasarkan latar belakang di atas maka dilakukan penelitian ini yang bertujuan untuk inventarisasi jenis alat tangkap baronang serta menentukan tingkat keramahan lingkungan unit penangkapan ikan baronang.

\section{METODE PENELITIAN}

Penelitian ini dilakukan di perairan Pulau Pramuka, Kepulauan Seribu DKI Jakarta. Penelitian akan dilaksanakan pada bulan Februari-Maret 2015 dan NovemberDesember 2015. Lokasi penelitian dapat dilihat pada Gambar 1 .

\section{Pengumpulan data}

Metode penelitian yang dilakukan adalah metode survei. Aspek yang dikaji dalam materi ini yaitu unit penangkapan ikan baronang dan tingkat keramahan lingkungan unit penangkapan perikanan baronang. Data yang digunakan dalam penelitian ini meliputi data primer dan sekunder. Data primer merupakan data hasil wawancara dengan nelayan yang dipilih metode berdasarkan random purposive sampling, sedangkan data sekunder berupa data produksi dan upaya penangkapan, harga dan alat tangkap ikan tembang yang diperoleh dari studi literatur, Dinas Kelautan dan Perikanan Provinsi Jakarta dan Suku Dinas Peternakan, dan Kelautan Kepulauan Seribu.

Data primerdiperoleh melaluiobservasi dan wawancara. Observasi yang dilakukan adalah mengikuti kegiatan penangkapan ikan dengan menggunakan alat tangkap muroami, jaring lingkar (tegur), bubu dan speargun. Operasi penangkapan dilakukan secara one day trip. Data untuk analisis tingkat keramah lingkungan alat penangkap ikan baronang dikumpulkan melalui wawancara langsung kepada 24 responden. Responden dalam penelitian ini terdiri 4 responden nelayan muroami, 4 responden nelayan jaring lingkar, 4 responden nelayan bubu kawat, 4 responden nelayan bubu jaring, 4 responden nelayan bubu tambun dan 4 responden nelayan speargun. Data yang diperlukan yaitu selektivitas alat tangkap, kualitas hasil tangkapan, metode penangkapan ikan hubungannya dengan kerusakan habitat dan biodiversity, hasil tangkapan utama dan sampingan (by catch), dan aspek sosial yang berhubungan dengan operasi penangkapan ikan baronang (konflik, ekonomi, sosial).

\section{Analisis data}

Tingkat keramahan lingkungan perikanan tangkap berdasarkan FAO (1995) diacu dalam Coning dan Witbooi (2015) tentang peraturan perikanan yang bertanggungjawab code of Conduct for Responsible Fisheries (CCRF). Kriteria dalam CCRF terdiri dari sembilan kriteria keramahan lingkungan yaitu (1) Alat tangkap harus memiliki selektivitas yang tinggi; (2) Alat tangkap tidak merusak habitat dan tempat hidup biota lainnya; (3) Tidak membahayakan nelayan; (4) Menghasilakan ikan yang bermutu baik; (5) Produksi tidak membahayakan konsumen; (6) Hasil tangkapan yang terbuang (by catch) 
minimum; (7) Alat tangkap yang digunakan harus memberikan dampak minimum terhadap keanekaan sumberdaya hayati (biodiversity); (8) Tidak menangkap jenis ikan yang dilindungi undang-undang dan terancam punah; (9) Dapat diterima secara sosial.

Analisis data untuk menentukan tingkat keramahan lingkungan unit penangkapan perikanan baronang berdasarkan sembilan kriteria tingkat keramahan lingkungan alat penangkapan ikan, selanjutnya dibuat empat sub kriteria pada masing-masing kriteria. Nanlohy (2013) membagi empat sub kriteria dengan skor yaitu sub kriteria A nilai skor 1, sub kriteria B nilai skor 2 , sub kriteria $\mathrm{C}$ nilai skor 3 dan sub kriteria D nilai skor 4 . Nilai skor maksimal dari nilai total skor adalah 36. Kajian kategori ramah lingkungan unit penangkapan perikanan baronang dibagi menjadi empat dengan rentang nilai skor pada Tabel 1

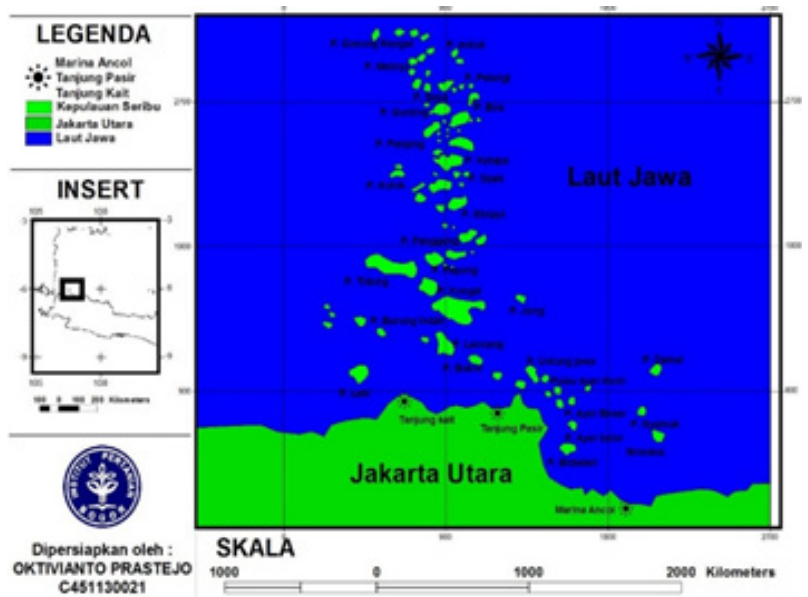

Gambar 1. Lokasi penelitian

Tabel 1. Kategori ramah lingkungan unit penangkapan perikanan baronang

\begin{tabular}{|c|c|c|}
\hline Skor & Bendera & Kategori \\
\hline $1-9$ & & Sangat tidak ramah lingkungan \\
\hline $10-18$ & & Tidak ramah lingkungan \\
\hline $19-27$ & & Ramah lingkungan \\
\hline $28-36$ & & Sangat ramah lingkungan \\
\hline
\end{tabular}

\section{HASIL DAN PEMBAHASAN}

Ikan baronang yang ditangkap oleh nelayan Kepulauan Seribu menggunakan berbagai jenis alat tangkap. Jenis alat tangkap yang digunakan adalah muroami, bubu tambun, bubu kompresor, jaring lingkar (tegur), speargun.

\section{Inventarisasi alat penangkapan ikan baronang}

\section{Muroami}

Muroami diklasifikasikan ke dalam golongan alat tangkap drive in net. Ada dua bagian utama dari alat tangkap muroami, yaitu jaring kantong dan jaring sayap. Sayap berfungsi sebagai penghalang untuk mengarahkan ikan yang digiring agar masuk ke dalam kantong. Kantong berfungsi sebagai tempat mengumpulkan ikan. Pengoperasian muroami dilakukan dengan cara ikan digiring menuju kantong jaring. Kantong jaring kemudian diangkat secara manual oleh beberapa nelayan menuju ke kapal. Dalam pengoperasian muroami terdapat beberapa alat bantu yang digunakan nelayan, diantaranya adalah GPS, sonar, keranjang, kecrik, kompresor dan alat bantu selam. Satu unit alat penangkapan muroami terdapat 15-18 orang nelayan yang memiliki tugas masingmasing. Pengoperasian muroami dapat dilihat pada Gambar 2.

Daerah penangkapan muroami terletak di perairan sekitar tubir karang, dimana ikan karang banyak berasosiasi di wilayah tersebut. Jenis ikan baronang yang tertangkap muroami adalah jenis Siganus javus, $S$. Vermiculatus, dan $S$. guttatus. Komposisi ikan baronang tertangkap oleh muroami hanya berkisar $23.50 \%$ dari keseluruhan hasil tangkapan. 


\section{Bubu tambun}

Bubu tambun (bubu bambu) termasuk dalam klasifikasi perangkap (trap). Bubu tambun dioperasikan di perairan dengan kedalaman 1-1,5 m, dimana hanya dioperasikan oleh satu orang nelayan. Jumlah bubu yang dipasang berjumlah 15 bubu. Jarak pemasangan antar bubu berkisar 5-10 m. Nelayan bubu turun ke perairan karang berpasir. Alat bantu nelayan pada saat menaruh bubu adalah masker dan sepatu karet. Bubu dipasang di perairan tanpa menggunakan pelampung tanda. Keberadaan bubu dapat diketahui dari tanda-tanda alam yang terdapat di sekitar lokasi pemasangan bubu. Pada saat pemasangan mulut bubu menghadap ke arah daratan, karena tingkah laku ikan karang yang mengikuti arus pada saat pasang surut (Iskandar 2011). Pemasangan bubu dapat dilihat pada Gambar 3 .

Ikan yang menjadi target penangkapan adalah ikan karang seperti kerapu, baronang, kakap, kakak tua, betok laut, dan ikan lencam. Daerah penangkapan di sekitar karang berpasir. Jenis ikan baronang yang tertangkap bubu tambun adalah jenis Siganus canaliculatus, $S$. guttatus, dan $S$. virgatus. Jenis baronang yang paling banyak tertangkap adalah jenis Siganus virgatus. Komposisi ikan baronang yang tertangkap bubu tambun berkisar $63.50 \%$ dari keseluruhan hasil tangkapan.

\section{Bubu kompresor}

Bubu kompresor adalah jenis bubu yang metode pengoperasiannya menggunakan alat bantu kompresor. Jenis bubu kompresor ada dua yaitu bubu kawat dan bubu jaring. Bentuk bubu kawat sama halnya dengan bubu tambun, perbedaan terletak pada bahan dasar bubu yaitu kawat. Bubu jaring berbentuk persegi (balok) dengan bahan penyangga berupa rangka yang terbuat dari besi dan ditutupi menggunakan jaring (PE). Kedua bubu memiliki metode pengoperasian yang sama yaitu memasang bubu pada kedalaman 5-20 m. Jumlah nelayan dalam pengoperasian bubu kompresor sekitar 5-7 orang. Jumlah bubu yang dipasang mencapai 20-30 bubu. Nelayan melakukan penyelaman dengan banuan kompresor untuk memasang bubu di periran karang. Pemasangan bubu diletakkan didekat karang yng terlindung dari arus dan diberikan pemberat berupa batu. Pemasangan bubu dan pengoperasiaan dapat dilihat pada Gambar 4.

Jenis ikan yang tertangkap oleh bubu kompresor adalah ikan karang, seperti ikan kerapu, lencam, baronang, kepe-kepe, ekor kuning, kaka tua, pisang-pisang dan kakap. Jenis ikan baronang yang tertangkap oleh bubu kompresor adalah jenis Siganus guttatus, $S$. virgatus, dan $S$. javus. Komposisi ikan baronang yang tertangkap bubu kompresor berkisar $42.15 \%$ dari keseluruhan hasil tangkapan.

\section{Jaring lingkar (tegur)}

Muroami diklasifikasikan ke dalam golongan alat tangkap jaring insang. Jaring lingkar dioperasikan dengan metode menyerupai jaring insang lingkar, dengan memutar jaring yang memiliki panjang 1-2 mil di periran karang berpasir. jaring dibentangkan dari pesisir pulau sampai kearah laut kemudian nelayan menggiring ikan dari arah laut menuju ke perairan dangkal sekitar pulau. Jaring yang dibentangkan kemudian diputar menuju wilayah pesisir. Jaring diputar terus menerus sehingga membentuk lingkaran yang semakin kecil. Ikan yang terjebak di dalam bentangan jaring segera digiring ke arah kantong yang dipasang di perairan dangkal. Kantong jaring kemudian diangkat ke atas kapal. Dalam pengoperasian jaring lingkar terdapat beberapa alat bantu yang digunakan nelayan, diantaranya adalah pengkocok, sepatu karet, masker, dan perahu sampan. Satu unit alat penangkapan jaring lingkar terdapat 7-10 orang nelayan yang memiliki tugas masing-masing. Metode pengoperasian jaring lingkar dapat dilihat pada Gambar 5.

Daerah penangkapan jaring lingkar terletak di perairan sekitar pesisir pulau yang memiliki dasar perairan karang dan pasir, dimana ikan karang banyak berasosiasi di wilayah tersebut. Jenis ikan baronang yang tertangkap jaring lingkar adalah jenis Siganus javus, S.virgatus, $S$. punctatus, $S$. canaliculatus dan $S$. guttatus. Komposisi ikan baronang tertangkap oleh jaring lingkar berkisar 73.15\% dari keseluruhan hasil tangkapan.

\section{Speargun}

Speargun termasuk ke dalam kelompok alat penangkapan ikan menjepit dan melukai (grappling and wounding). Alat tangkap speargun yang digunakan nelayan terbuat dari batang kayu, logam atau bahan lainnya yang mempunyai satu atau lebih bagian runcing/tajam, pengoperasiannya dengan cara mencengkram, mengait/ menjepit, melukai, dan/atau membunuh sasaran tangkap. Jumlah nelayan dalam pengoperasian speargun sebanyak 5-6 orang. Alat bantu utama penangkapan ikan yang digunakan nelayan speargun adalah kompresor, senter kedap air dan masker selam. Beberapa alat bantu lainnya juga digunakan oleh nelayan untuk mendukung operasi penangkapan ikan. Menurut Mubarok 2012, alat bantu lain diantaranya adalah fin (kaki katak), coral boot, sarung tangan, wetsuit (pakaian untuk menghambat penurunan panas tubuh) dan pemberat. Pengoperasian speargun dilakukan pada malam hari sekitar pukul 19:00-02:00. Pengoperasian malam dilakukan untuk mempermudah proses penangkapan ikan, karena pada waktu malam kebiasaan ikan karang tertidur dan cenerung pasif (Mubarok et al. 2012). Pengoperasian speargun dapat dilihat pada Gambar 6. 
Daerah penangkapan nelayan speargun adalah sekitar terumbu karang dengan kedalaman 3-10 m, dimana ikan karang tinggal dan berlindung di wilayah tersebut. Jenis ikan karang yang menjadi target penangkapan adalah ikan ekor kuning, baronang, kerapu, dan teripang. Jenis ikan baronang yang ditangkap oleh nelayan speargun adalah jenis Siganus javus, S.vermiculatus, S. punctatus, S. canaliculatus dan S. guttatus. Komposisi ikan baronang tertangkap oleh speargun berkisar 73,15 \% dari keseluruhan hasil tangkapan.

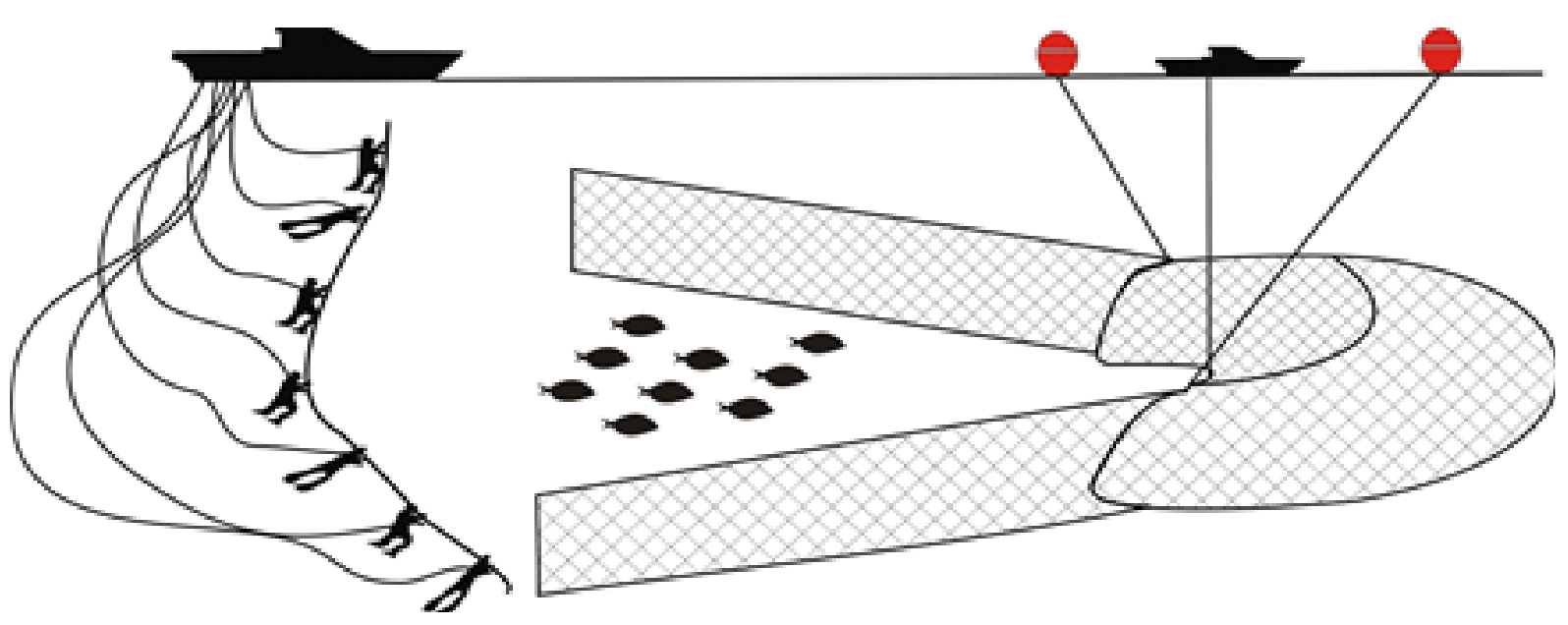

Gambar 2. Metode operasi penangkapan dengan alat muroami

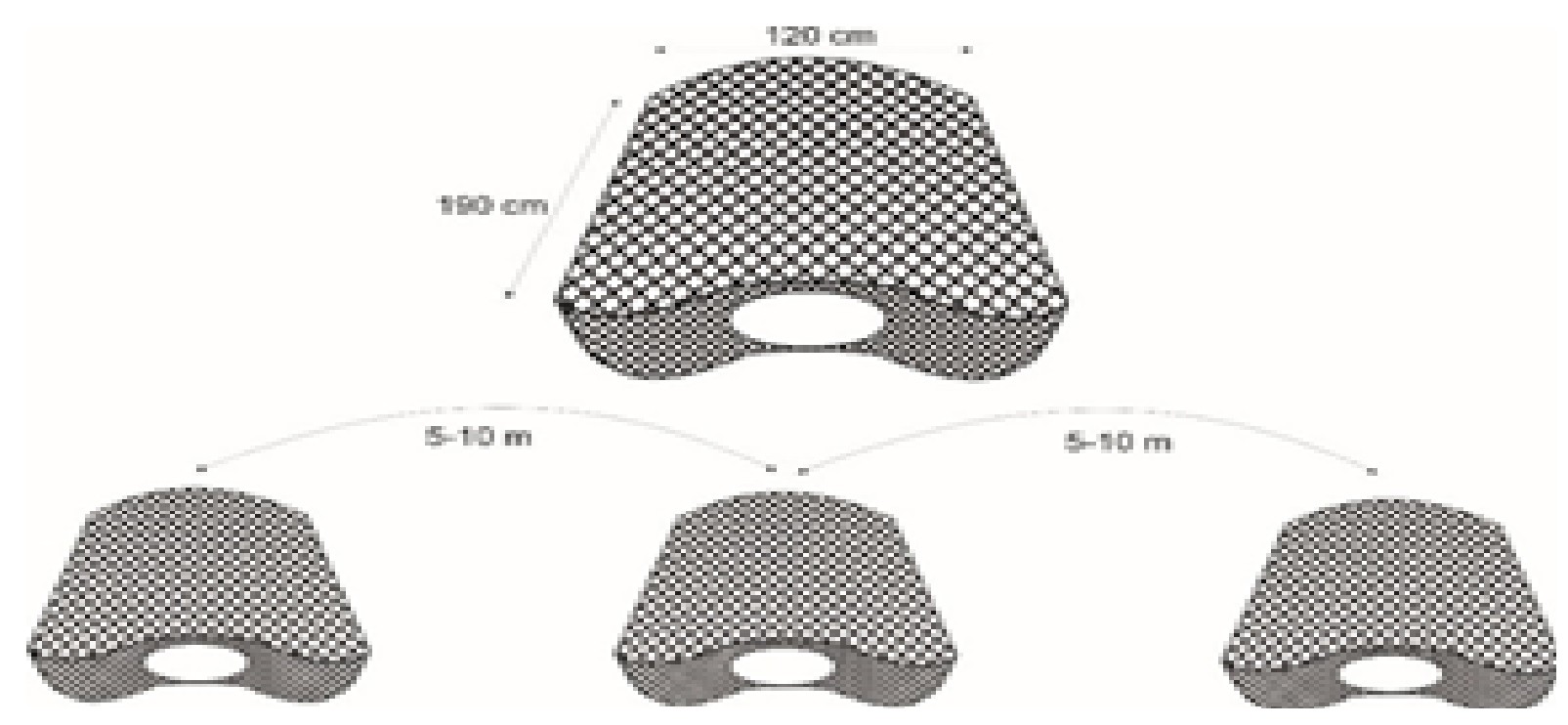

Gambar 3. Bubu tambun 


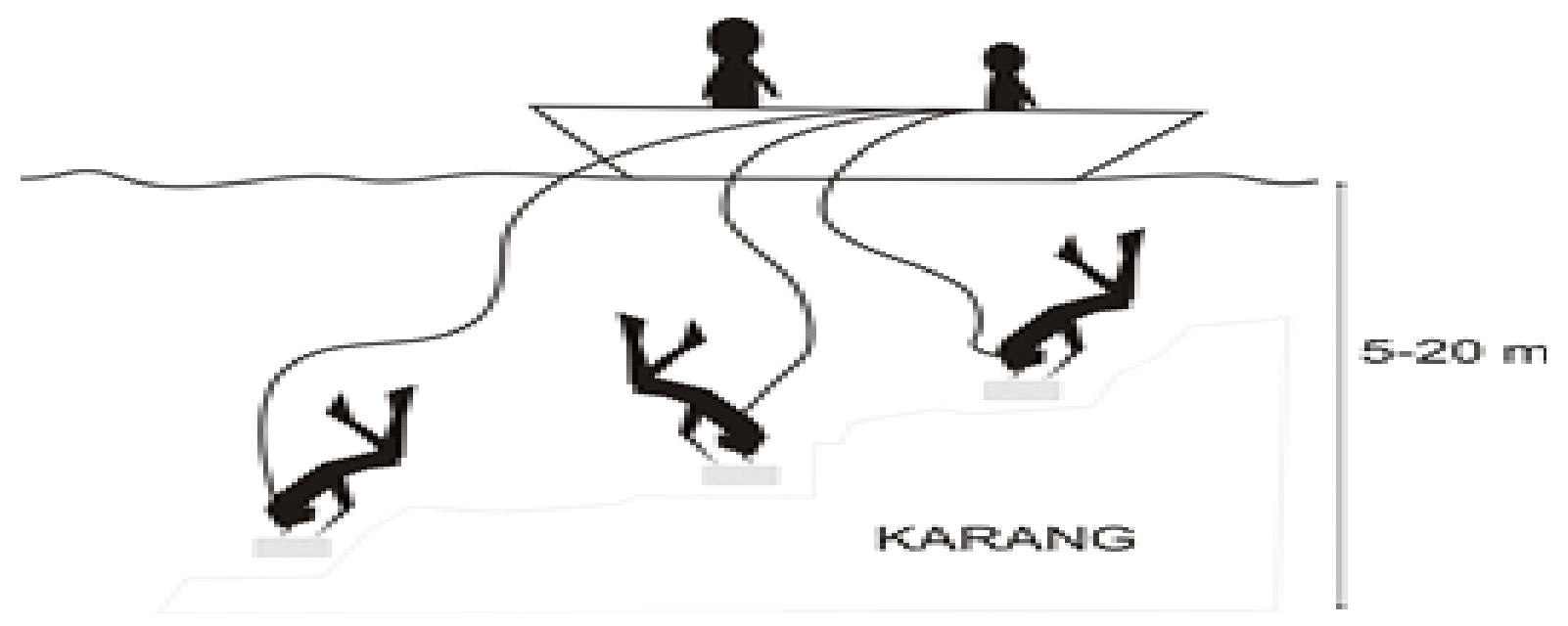

Gambar 4. Metode operasi penangkapan dengan bubu kompresor

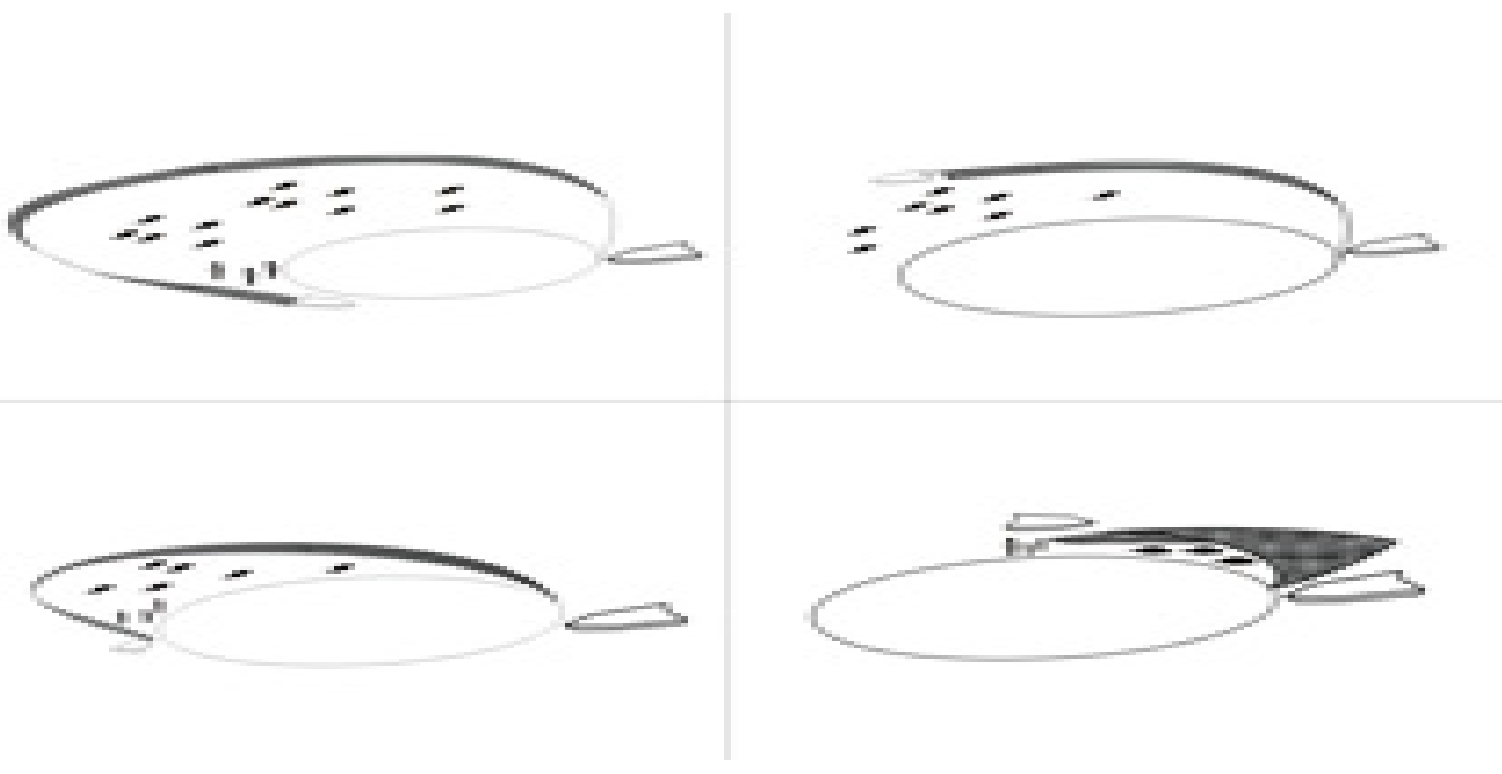

Gambar 5. Metode operasi penangkapan dengan jaring lingkar

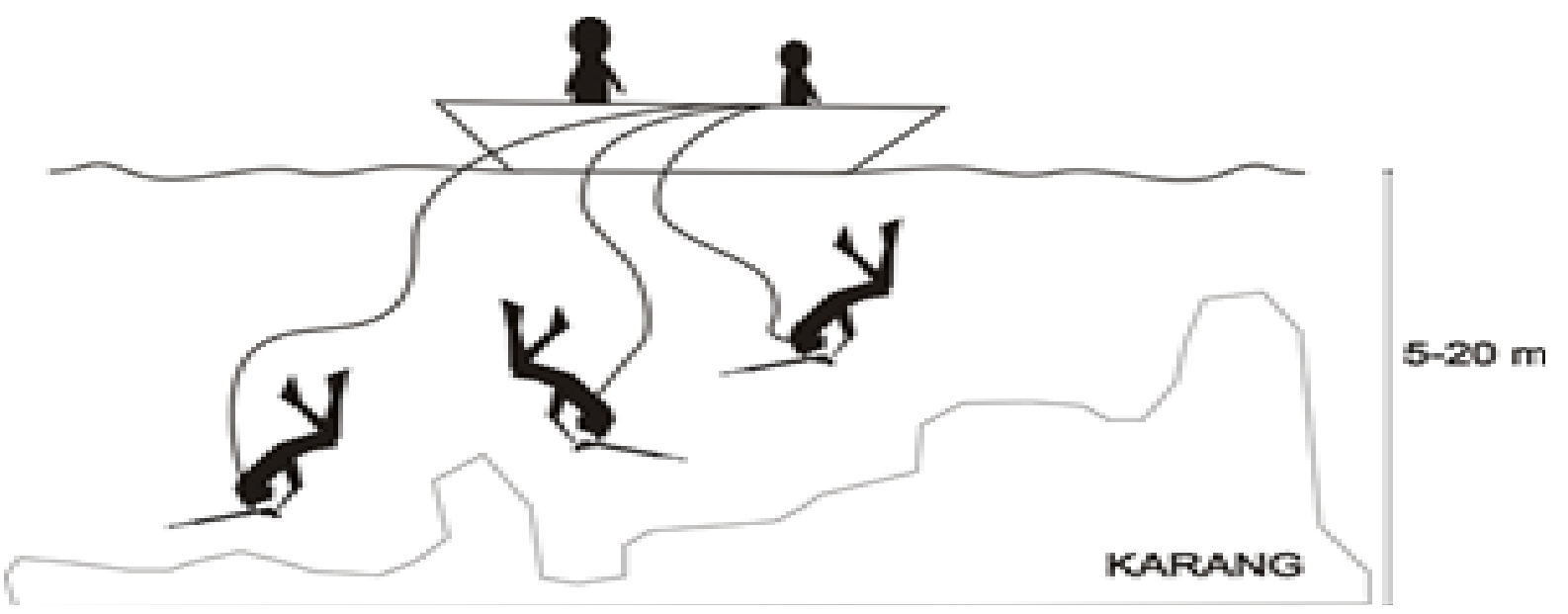

Gambar 6. Metode operasi penangkapan dengan speargun 


\section{Analisis tingkat keramahan lingkungan alat tangkap baronang}

Hasil analisis tingkat keramahan lingkungan alat tangkap baronang pada sembilan kriteria alat tangkap ramah lingkungan disajikan pada Tabel 2.

Penilaian skor diambil dari hasil wawancara dengan setiap responden ada 4 nelayan per jenis alat tangkap. Skor tertinggi dari keseluruhan kriteria terdapat pada alat tangkap bubu tambun dengan nilai 25.75. Skor terendah dari kesembilan kriteria adalah alat tangkap muroami dengan nilai
16.25. Kategori alat tangkap yang ramah lingkungan dapat dilihat pada Tabel 3.

Hasil analisis terhadap sembilan kriteria tingkat keramahan lingkungan alat tangkap baronang menunjukkan alat tangkap yang tidak ramah lingkungan adalah jenis alat muroami dan jaring lingkar, sedangkan alat tangkap yang ramah lingkungan adah bubu tambun, bubu kawat, bubu jaring, dan speargun. Bubu tambun merupakan jenis alat tangkap yang paling ramah lingkungan dibandingkan kelima jenis alat tangkap lain.

Tabel 2. Distribusi ikan demersal di Perairan Pulau Ambon berdasarkan wilayah penangkapan dan musim

\begin{tabular}{|c|c|c|c|c|c|c|c|}
\hline \multirow[b]{2}{*}{ No } & \multirow[b]{2}{*}{ Kriteria } & \multicolumn{6}{|c|}{ Alat tangkap } \\
\hline & & Muroami & $\begin{array}{l}\text { Bubu } \\
\text { tambun }\end{array}$ & $\begin{array}{l}\text { Bubu } \\
\text { kawat }\end{array}$ & $\begin{array}{l}\text { Bubu } \\
\text { jaring }\end{array}$ & $\begin{array}{l}\text { Jaring } \\
\text { lingkar }\end{array}$ & Speargun \\
\hline 1 & $\begin{array}{l}\text { Memiliki selektivitas } \\
\text { yang tinggi }\end{array}$ & 1.25 & 1.00 & 1.25 & 1.00 & 1.00 & 3 \\
\hline 2 & $\begin{array}{l}\text { Tidak merusak habi- } \\
\text { tat, tempat tinggal dan } \\
\text { berkembang biak ikan } \\
\text { dan organisme lain- } \\
\text { nya. }\end{array}$ & 1.25 & 3.00 & 2.00 & 1.50 & 1.50 & 3.75 \\
\hline 3 & $\begin{array}{l}\text { Proses penangkapan } \\
\text { ikan tidak membahay- } \\
\text { akan nelayan }\end{array}$ & 1.00 & 2.75 & 1.50 & 1.50 & 1.25 & 1.00 \\
\hline 4 & $\begin{array}{l}\text { Hasil tangkapan ber- } \\
\text { mutu baik }\end{array}$ & 1.50 & 3.75 & 3.25 & 3.00 & 2.00 & 2.25 \\
\hline 5 & $\begin{array}{l}\text { Produk tidak memba- } \\
\text { hayakan kesehatan } \\
\text { konsumen }\end{array}$ & 2.50 & 4.00 & 4.00 & 4.00 & 3.25 & 3.25 \\
\hline 6 & $\begin{array}{l}\text { Hasil tangkapan samp- } \\
\text { ingan sedikit }\end{array}$ & 2.25 & 2.00 & 2.00 & 1.75 & 2.50 & 3.25 \\
\hline 7 & $\begin{array}{l}\text { Alat tangkap memberi- } \\
\text { kan dampak terha- } \\
\text { dap keanekaragaman } \\
\text { Sumberdaya hayati }\end{array}$ & 1.50 & 2.00 & 1.50 & 2.50 & 1.00 & 3.75 \\
\hline 8 & $\begin{array}{l}\text { Tidak menangkap bi- } \\
\text { ota yang dilindungi } \\
\text { undang-undang atau } \\
\text { terancam punah }\end{array}$ & 4.00 & 3.25 & 3.25 & 3.25 & 3.25 & 2.25 \\
\hline 9 & $\begin{array}{l}\text { Alat tangkap diterima } \\
\text { secara sosial }\end{array}$ & 1.00 & 4.00 & 3.00 & 3.00 & 2.00 & 1.75 \\
\hline & Skor & 16.25 & 25.75 & 21.75 & 21.50 & 17.75 & 23.50 \\
\hline
\end{tabular}


Tabel 3. Kategori alat tangkap baronang

\begin{tabular}{|c|c|c|c|}
\hline Alat tangkap & Skor & Bendera & Kategori \\
\hline Muroami & 16.25 & & Tidak ramah lingkungan \\
\hline Bubu tambun & 25.75 & & Ramah lingkungan \\
\hline Bubu kawat & 21.75 & & Ramah lingkungan \\
\hline Bubu jaring & 21.50 & & Ramah lingkungan \\
\hline Jaring Lingkar & 17.75 & & Tidak ramah lingkungan \\
\hline Speargun & 23.50 & & Ramah lingkungan \\
\hline
\end{tabular}

\section{KESIMPULAN DAN SARAN}

\section{Kesimpulan}

Jenis alat tangkap ikan yang menangkap baronang di Kepulauan Seribu adalah alat tangkap muroami, bubu tambun, bubu kawat, bubu jaring, jaring lingkar, dan speargun. Dari tingkat keramah lingkungan jenis alat tangkap bubu tambun merupakan alat tangkap yang paling ramah lingkungan dengan nilai skor 25.75.

\section{Saran}

Perlu adanya perbaikan alat tangkap yang tidak ramah lingkungan, agar kelestarian ikan baronang di Kepulauan Seribu tetap terjaga.

\section{DAFTAR PUSTAKA}

Arthana IW. 2009. Komunitas ikan karang di Pantai Sawangan dan Kutuh, Bali. Jurnal Bumi Lestari. 9(2): 224 - 232

Bubun RL, Mahmud A. 2015. Komposisi hasil tangkapan pukat cicin hubungannya dengan teknologi penangkapan ikan ramah lingkungan. Marine Fisheries. 6(2): 15-26.

Caddy JF, Seijo JC. 2005. This is more dificult tan we thought. The Responsibility of Scientists, Manager and Stakeholders to Mitigate the Unsustainability of Marine Fisheries. Phil Trans R Soc. B. (360): 59-75

Coning E, Witbooi E. 2015. Towards a New'fisheries Crime' Paradigm: South Africa as an Illustrative Example. Marine Policy. 60(2015): 208-215.

Iskandar DM, Puspita. 2009. Efisiensi Teknis dan Ekonomis Unit Penangkapan Muroami Pulau Pramuka, Kabupaten
Kepulauan Seribu. Jurnal Mangrove dan Pesisir. 9(2): 80-86.

Iskandar D. 2011. Analisis hasil tangkapan sampingan bubu yang dioperasikan di perairan karang Kepulauan Seribu. Jurnal Saintek Perikanan. 6(2): 31-37.

FAO. 2015. Fish Base [internet]. [diunduh pada Maret 2016]. Tersedia pada http: / / www.fao.org.

Mayunar. 1992. Beberapa Aspek Ikan Baronang (Siganus canaliculatus). Oseana. 18(4): 177-193.

Mubarok HA, Wisudo $\mathrm{SH}$, Iskandar $\mathrm{BH}$. 2012. Status perikanan panah di Kepulauan Karimunjawa Kabupaten Jepara Jawa Tengah berdasarkan CCRF. Jurnal Marine Fisheries. 3(2): 115-22.

Nanlohy AC. 2013. Evaluasi alat tangkap ikan pelagis yang ramah lingkungan di Perairan Maluku dengan menggunakan prinsip CCRF (Code of Conduct for Responsible Fisheries). Jurnal Ilmu Hewan Tropika. 2(1): $1-11$.

Purnomo T, Hariyadi S, Yonvitner. 2013. Kajian potensi perairan dangkal untuk pengembangan wisata bahari dan dampak pemanfaatannya bagi masyarakat sekitar (studi kasus Pulau Semak Daun sebagai daerah penunjang kegiatan wisata Pulau Pramuka Kabupaten Administrasi Kepulauan Seribu). Jurnal Departemen Perikanan dan Ilmu Kelautan. 2(3): 172-183.

Riyanto M, Purbayanto A, Nugraha A. 2009. Efektivitas penangkapan ikan karang konsumsi menggunakan bubu berumpan di Kepulauan Seribu. Prosiding Perikanan Semarang Expo. 2009: 114-120. 